\title{
Evolution of Flow-Diverter Endothelialization and Thrombus Organization in Giant Fusiform Aneurysms after Flow Diversion: A Histopathologic Study
}

I. Szikora, E. Turányi, and M. Marosfoi

ow

\begin{abstract}
BACKGROUND AND PURPOSE: Treatment of giant fusiform aneurysms with flow diverters has been associated with a relatively high rate of complications. Our goal was to study the evolution of flow-diverter endothelialization and thrombus organization at different time points after flow-diverter treatment in giant fusiform aneurysms to better understand reasons for flow-diverter thrombosis and delayed aneurysm ruptures.
\end{abstract}

MATERIALS AND METHODS: Two giant anterior and 2 posterior circulation aneurysms, all of which had partially thrombosed before treatment, were studied. An unruptured, untreated posterior circulation aneurysm was used as a control. Each specimen was removed at 7 days or at 6, 9, or 13 months after flow-diverter treatment. The 3 patients who survived longer than 7 days were followed up by angiography and MR imaging. Formaldehyde-fixed paraffin-embedded sections were stained by using H\&E, Van Gieson elastic, CD34, h-Caldesmon, and Picrosirius stains and studied by light microscopy.

RESULTS: According to angiography, aneurysms were found to be obliterated partially at 6 and 9 months and completely at 13 months. MR imaging revealed that mass effect remained unchanged in each case. Sections of the flow diverter within the normal parent artery were covered by an endothelialized fibrous layer as early as 6 months, but there was no tissue coverage or endothelialization seen even at 13 months inside the aneurysm itself. Each treated aneurysm had a thin wall with complete lack of smooth muscle cells. No signs of thrombus organization were found at any of the time points studied.

CONCLUSIONS: Endothelialization of the flow diverter in giant fusiform aneurysms may not occur and thrombus organization may not be initiated inside these aneurysms for as long as 1 year, which explains delayed flow-diverter thrombosis and the possibility of delayed ruptures.

ABBREVIATIONS: GFA = giant fusiform aneurysm; $F D$ = flow diverter; $P E D=$ Pipeline embolization device

B ecause of the limited efficacy of endovascular coil packing, intravascular flow diversion has been proposed recently for large and giant aneurysms. ${ }^{1-6}$ The relative safety and high efficacy of flow diversion in saccular aneurysms presenting with mass effect have been reported. ${ }^{1,7,8}$ However, a high rate of thromboem-

Received July 19, 2014; accepted after revision February 4, 2015

From the National Institute of Clinical Neurosciences (I.S., M.M.), Budapest, Hungary; and lst Department of Pathology (E.T.), Semmelweis University Medical School, Budapest, Hungary.

This study was supported in part by grant KTIA_NAP_13-1-2013-0001 from the National Brain Research Program of Hungary.

Paper previously presented in part at: 12th Congress of the World Federation of Interventional and Therapeutic Neuroradiology (WFITN), November 9-13, 2013; Buenos Aires, Argentina.

Please address correspondence to I. Szikora, National Institute of Clinical Neurosciences, Amerikai ut 57, H-1145 Budapest, Hungary; e-mail: h13424szi@ella.hu

-- Indicates open access to non-subscribers at www.ajnr.org

三 Indicates article with supplemental on-line tables.

http://dx.doi.org/10.3174/ajnr.A4336 bolic and hemorrhagic complications has been found in giant fusiform aneurysms (GFAs), particularly in those located in the posterior fossa. ${ }^{9,10}$

Flow diversion is expected to produce aneurysm thrombosis and facilitate subsequent thrombus organization. Simultaneously, the flow diverter (FD) is supposed to become covered by an intimal layer, sealing the aneurysm cavity from the parent artery and preventing it from thromboembolic complications. Considering the poor results in giant fusiform aneurysms, it was reasonable to assume that one or both of these mechanisms did not work as expected in these lesions. The primary purpose of this study was to investigate the efficacy of these processes in GFAs. We also analyzed whether the clinical problems were related to the location (posterior circulation) or the morphology of aneurysms.

\section{MATERIALS AND METHODS Treatment and Follow-Up}

A total of 5 GFAs were studied as approved by our institutional internal review board. One unruptured, nonthrombosed, and 


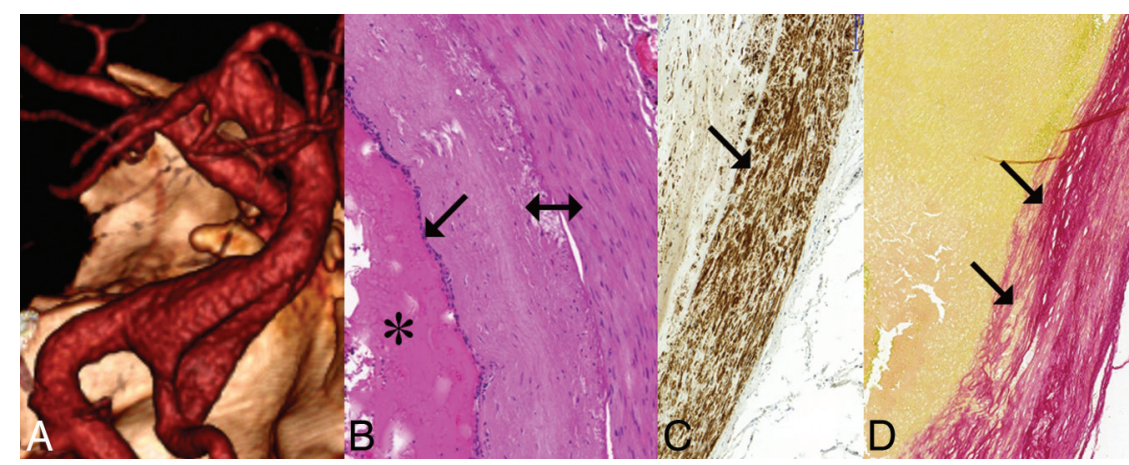

FIG 1. Unruptured, nonthrombosed giant fusiform aneurysm involving the vertebrobasilar junction. $A$, Volume-rendering 3D reconstruction of a CTA, demonstrating fusiform aneurysm of the vertebrobasilar junction. $B$, Histologic section of the fusiform aneurysm showing fresh clot inside the aneurysm (star), intact elastic lamina (arrow), and thick aneurysm wall (double arrow) (H\&E staining). C, Section of the aneurysm wall showing a thick layer of smooth muscle cells (arrow) (h-Caldesmon staining). $D$, Section of the aneurysm wall showing a thick subintimal layer of connective tissue (Picrosirius staining) (arrows) and no connective tissue invasion into the thrombus inside the aneurysm, indicating a lack of thrombus organization. of the FD, to the structure of the aneurysm wall, and any signs of smooth muscle cell invasion or connective tissue formation inside the intra-aneurysmal clot, indicating thrombus organization.

\section{RESULTS \\ Case 1: Untreated GFA of the Vertebrobasilar Junction}

The cavity of this control aneurysm was filled with fresh thrombus. The aneurysm wall was well structured and had a strong muscular layer. There were no signs of inflammation within the wall or any signs of thrombus organization by immunohistochemistry within the cavity (Fig 1, On-line Table 2). untreated aneurysm was removed 7 days after the patient died as a result of a stroke in the brain stem. This aneurysm was used as a control. Each of the other ones was partially thrombosed, treated with an FD, and removed at 7 days or 6, 9, or 13 months after the treatment after the patients died as a result of either hemorrhagic or thromboembolic complications. Two of these aneurysms were located in the posterior and the other 2 in the anterior circulation, and all were symptomatic. Alternative surgical or endovascular treatment options, including parent artery occlusion, were discussed with each patient and excluded after multidisciplinary consultation in each case. Of the 4 patients, 3 were treated with double antiplatelets (100 mg of acetylsalicylic acid and $75 \mathrm{mg}$ of clopidogrel) before and during their follow-up period; the fourth patient (patient 5) (On-line Table 1) was on dual antiplatelets for 9 months and single-antiplatelet therapy with clopidogrel afterward. Platelet functions were tested by the Platelet Function Assay (PFA 100; Siemens Medical Systems, Erlangen, Germany), adenosine diphosphate closure time (ADP-CT; Siemens), and the Innovance PY2 test (Siemens) and found to be sufficiently inhibited before the procedure. No further tests were performed during the follow-up. Four- to 5-mm-diameter telescopic Surpass FDs (Stryker Neurovascular, Kalamazoo, Michigan) were used in both posterior circulation aneurysms, and double-layer 3.5- to 4.5$\mathrm{mm}$-diameter Pipeline embolization devices (PEDs) (Covidien, Irvine, California) were applied in the anterior circulation aneurysms. All patients were scheduled for follow-up MR imaging and DSA studies at 5-6 and 12 months after the procedure. All the patients received methylprednisolone $(2 \times 250 \mathrm{mg} /$ day $)$ for at least 2 days before and 3-5 days after the procedure, and the dose was decreased gradually afterward (On-line Table 1).

\section{Histopathologic Analysis}

Each aneurysm was removed during autopsy, fixed in buffered formaldehyde, sectioned, and stained with H\&E and Van Gieson elastic stains. For immunohistochemistry, CD34 was used to demonstrate endothelium, h-Caldesmon to visualize smooth muscle cells, and Picrosirius to detect connective tissue. Sections were studied by light microscopy. Special attention was given to the identification of any tissue coverage on the internal surface

\section{Case 2: GFA of the Vertebrobasilar Junction 7 Days after FD Treatment}

The patient died as a result of SAH related to an intraprocedural aneurysm rupture. No tissue layer was found covering the internal surface of the FD. The aneurysm cavity was filled with unorganized thrombus. The aneurysm wall was thin and fragmented with no smooth muscle cells identified in it (On-line Table 2).

\section{Case 3: Partially Thrombosed GFA of the MCA}

This patient died as a result of a major MCA infarct that developed because of occlusion of one of the M2 branches distal to the FD 6 months after the procedure implanting the FD.

A section of the FD placed within the normal artery proximal to the aneurysm was covered by a thick tissue layer consisting of smooth muscle cells and covered by a single endothelial cell layer corresponding to intimal hyperplasia. The FD inside the aneurysm was free of any tissue coverage. The GFA was filled with unorganized clot only, despite most of the aneurysm not being filled with contrast material (as detected by angiography at 6 months). There were no signs of smooth muscle cell invasion or connective tissue formation inside the thrombus. The aneurysm wall was thick and fragmented and showed signs of chronic inflammation, including lymphocytes and macrophages (Fig 2, Online Table 2).

\section{Case 4: GFA of the Vertebrobasilar Junction 9 Months after FD Treatment}

This patient reportedly died as a result of a brain stem infarct, but no MR imaging was performed to confirm the diagnosis. The FD was patent, and its internal surface was covered by a thin fibrin layer only, with no smooth muscle cells or endothelial lining. The aneurysm was filled with fresh thrombus. There were no signs of clot organization. According to MR imaging and angiography, the size and filling of this aneurysm did not change at 6 months. The wall of the aneurysm was thin and fragmented (On-line Table 2).

\section{Case 5: GFA of the ICA 13 Months after FD Treatment}

This patient died as a result of a major MCA infarct that developed after a sudden thrombosis of the FD construct, as confirmed by 


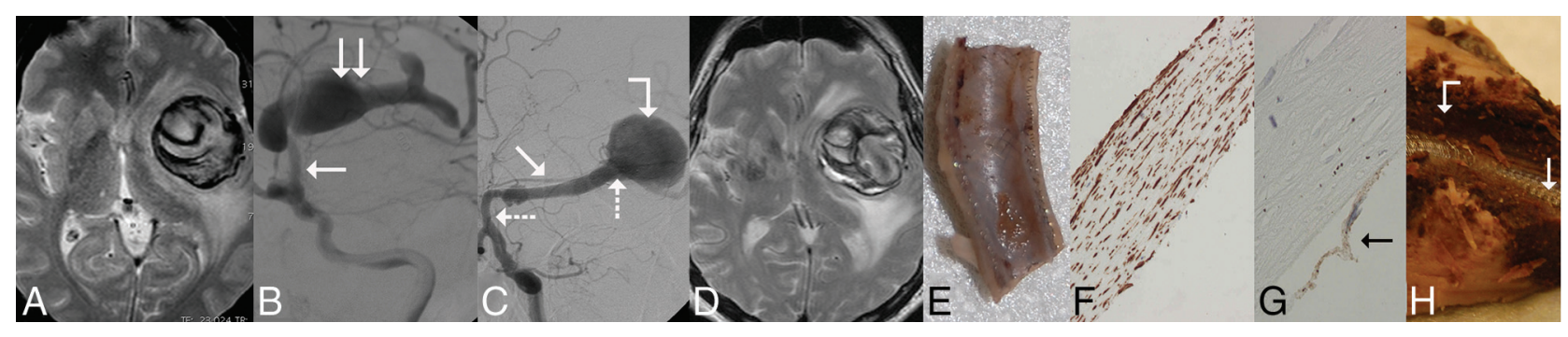

FIG 2. Giant, partially thrombosed, fusiform aneurysm of the left MCA treated with a construct of 2 Pipeline embolization devices; the specimen was removed 6 months after PED implantation. A, T2-weighted MR image before treatment, showing large mass of mixed signal intensity, associated with significant mass effect and white matter edema, consistent with a giant aneurysm. $B$, DSA of the same aneurysm. The arrow points to the proximal, normal portion of the $\mathrm{Ml}$ section. and the double arrow points to the fusiform aneurysm expending into the $\mathrm{M} 2$ sections. C, Follow-up DSA 6 months later showing "angiographic reconstruction" of the distal M1 section (arrow), significant enlargement of the dilated proximal section of the cranial M2 branch (bent arrow), and lack of filling (occlusion) of this branch distal to the dilation. The PED construct can be seen between the 2 dotted arrows. D, Follow-up T2-weighted MR image from 6 months after treatment showing unchanged mass effect, edema, and mixed signal intensity. E, Longitudinal cut of the proximal landing zone. The luminal surface of the PED is covered by a smooth tissue layer. F, Microscopic section of the layer removed from the luminal surface of the PED showing neointimal growth consisting of smooth muscle cells (h-Caldesmon staining). $G$, The same layer is covered by a single cell layer of endothelium (arrow) (CD34 staining). $H$, Macroscopic cross-section of the specimen at the level of the fusiform aneurysm. The implanted PED construct (arrow) is uncovered and surrounded by fresh clot (bent arrow).
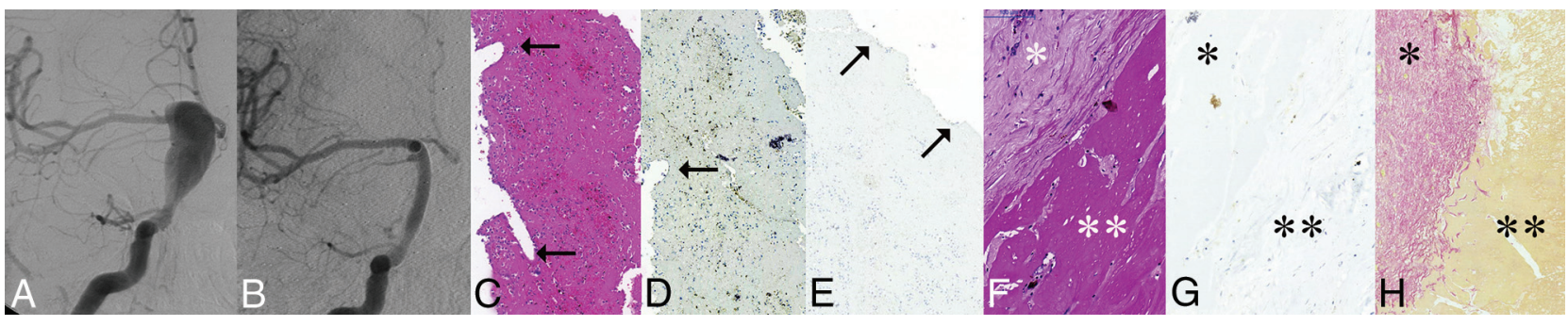

FIG 3. Giant, partially thrombosed fusiform aneurysm of the right ICA treated by a construct of 2 PEDs. The specimen was removed 13 months after treatment. A, DSA before treatment showing the circulating portion of the partially thrombosed GFA involving the supraclinoid ICA on the right. $B$, DSA 1 year after treatment showing angiographic reconstruction of the entire length of the fusiform aneurysm. $C$. Thin fibrin layer removed from the luminal surface of the PED construct by H\&E staining. The arrows in $C$ and $D$ point to the impressions of the flow-diverter struts on the outer surface of the fibrin layer. $D$, h-Caldesmon staining fails to show smooth muscle cells inside this layer. $E$, CD34 fails to show endothelial coverage on the luminal surface (arrows) of the layer. F. Histologic section showing a thick aneurysm wall with low cell attenuation (star) and fresh thrombus underneath the wall (double star) by H\&E staining. G, h-Caldesmon staining fails to show any smooth muscle cells within the wall (star) or invasion into the clot (double star). H, Picrosirius staining reveals subintimal connective tissue within the thick aneurysm wall (star) but no invasion into the thrombus (double star).

DSA 1 month after the last angiography, while still on a singleantiplatelet therapy with clopidogrel.

The internal surface of the FD inside the aneurysm was covered again by a thin fibrin layer only. Despite the aneurysm not being visible by angiography, the cavity of the aneurysm was filled with fresh clot only. There were signs of chronic inflammation inside the wall, which contained no smooth muscle cells. There were no signs of smooth muscle cell invasion or any other signs of thrombus organization (Fig 3, On-line Table 2).

MR imaging showed that regardless of the angiographic occlusion of the GFA, none of the treated aneurysms changed in either size or signal intensity throughout the follow-up period up to 9 months (Fig 2). No perforator occlusions were identified in any of the follow-up angiograms.

\section{DISCUSSION}

Fusiform aneurysms of the circle of Willis represent 3\%-13\% of all intracranial aneurysms, with most located in the posterior circulation. ${ }^{11}$ Their etiology is unclear; both atherosclerosis and dissection have been proposed as pathogenetic factors. ${ }^{12}$ Some may present with subarachnoid hemorrhage, and these are generally considered dissecting aneurysms. ${ }^{13}$ Others may grow very large or giant and become symptomatic via neural compression or ischemia. The clinical course is generally progressive and, without successful treatment, almost always devastating.

Treatment options are limited. Drake and Peerless ${ }^{14}$ reported the results of 120 patients surgically treated for GFAs. Seventy-six percent of these patients with an anterior circulation GFA had a good outcome, whereas only $67 \%$ of those with a vertebrobasilar aneurysm had a good outcome. The treatment mostly included parent artery occlusion. In a more recent series, 6 of 9 symptomatic lesions resulted in poor outcomes ( 1 with bypass surgery, 1 with attempted clipping, and 4 with no intervention). Only those for whom parent artery occlusion was feasible fared well. ${ }^{15}$

Among the endovascular techniques, parent artery occlusion remains the best option for those with good collateral circulation. ${ }^{16}$ Reconstructive endovascular techniques, including FD-supported coiling or double-FD implantation, have been successfully applied for smaller fusiform aneurysms ${ }^{17,18}$ but not for giant ones.

The introduction of FDs raised enthusiasm regarding reconstructive treatment of hardly treatable intracranial aneurysms, including GFAs. Fiorella et al ${ }^{19-21}$ reported 4 such patients successfully treated by FD implantation and coil packing. However, these 
publications were soon followed by reports on late complications, including late thrombosis of the FD within 2 years. ${ }^{9}$ Of 13 delayed ruptures after FD treatment reported by Kulcsár et al, ${ }^{22} 4$ were in patients with a GFA. In a series by Siddiqui et al, ${ }^{10}$ after FD treatment for posterior circulation GFAs in 7 patients, 4 patients died and 2 had a poor outcome.

This study was undertaken to investigate potential reasons for such poor results, particularly when compared with the better outcomes achieved in patients with saccular aneurysms, even when those aneurysms were large or giant. ${ }^{1}$ In general, the low efficacy of coil packing in giant aneurysms is attributed to the inability of the coils to induce permanent thrombosis and endothelial lining of the neck. In such lesions, thrombus organization and neck endothelialization were not found 2-6 months after treatment with coils. ${ }^{23}$ FDs are expected to initially induce aneurysm thrombosis by intra-aneurysmal flow reduction and to seal the aneurysm cavity off from the circulation by inducing neointimal coverage of the FD surface at the neck. This seal would allow the intrasaccular thrombus to be eventually organized. In animal models, neointimal lining of the PED has been demonstrated as early as 7 days after implantation in normal arterial sections and 4-8 weeks after treatment across the neck of saccular aneurysms. ${ }^{24,25}$ Studies on the endothelialization of FDs in human subjects have not been reported yet. We hypothesized that the reason for the poor results in GFAs was the lack of thrombus organization inside the aneurysm, the lack of intimal coverage of the FD, or both. Thrombus organization was expected to be visualized in the form of smooth muscle cell invasion and connective tissue formation within the clot. ${ }^{26}$ Intimal growth over the luminal surface of the FD device was expected to be seen as a tissue layer consisting of smooth muscle cells covered by endothelium.

The design of the FD did not seem to make any difference. Two types were used, and each diameter was chosen to match the diameter of the normal artery proximal and distal to the fusiform dilation as closely as possible. Because of the fusiform nature of the aneurysms, all the FDs were fully opened and reached their nominal diameter inside the aneurysm. Subsequently, the deviceto-vessel diameter ratio did not affect the final metal coverage, which is supposed to be approximately $30 \%$ for each device. The Surpass device had higher pore attenuation than the PED (20-32 and $15-22$ pores $/ \mathrm{mm}^{2}$, respectively), but that did not influence the histologic outcome up to 9 months after treatment (On-line Table 1, patient 4).

The wall of the nonthrombosed control aneurysm contained a thick layer of smooth muscle cells consistent with myointimal hyperplasia. ${ }^{27}$ In contrast, the walls of all treated aneurysms were fragmented with low cell attenuation, signs of inflammation, and a lack of smooth muscle cells. Inside the GFAs, there were no signs of smooth muscle cell invasion or connective tissue formation indicating clot organization, regardless of the length of follow-up (for as long as 13 months) and regardless of occlusion or patency of the aneurysm as seen on angiography. Clinical experience and experimental evidence have shown that the loss of mural cells is associated with an inability to transform intraluminal thrombus to stable scar tissue because of the lack of smooth muscle cells inside the wall. ${ }^{28}$ Subsequently, the lack of thrombus organization is likely to be related to cellular loss of the sick wall in our GFAs.
All the treated aneurysms were partially thrombosed before treatment, which is likely to be the reason for their wall degeneration. The release of thrombocyte-derived growth factors and peroxidases from the luminal thrombus, together with deoxygenation of stagnating red blood cells and a subsequent lack of oxygen, are supposed to trigger cell death and inflammation inside the wall. ${ }^{27}$ FDs may significantly reduce flow velocity within the aneurysm but cannot repair the aneurysm wall and facilitate clot organization because of the pre-existing lack of necessary smooth muscle cells. In fact, the stagnation induced by the FD may trigger further release of substances, such as matrix metalloproteinases, that damage the aneurysmal wall and increase the risk of rupture. ${ }^{22,29}$

Histology showed lack of thrombus organization, which was consistent with MR imaging findings, which showed no change in signal intensity or size of the aneurysms during the follow-up period. Considering that simultaneous angiography showed partial or complete occlusion of the aneurysm and reconstruction of the parent artery, one must keep in mind that nonfilling of an aneurysm by angiography indicates only that blood is not flowing inside the aneurysm any more, but it certainly does not indicate healing of the aneurysm.

Intimal coverage is necessary for preventing FD thrombosis without aggressive antiplatelet medication. In our patients, only the section of FD implanted within the normal parent artery and circumferentially covered by normal arterial wall got covered by neointima and endothelialized as early as 6 months (patient 3 ). The portion of the FD inside the GFA without any contact with normal vascular wall remained uncovered, and no endothelial cells were found at any time point inside the aneurysms for as long as 13 months after treatment. This finding is similar to the lack of endothelialization seen in aortic FD grafts. ${ }^{30}$ Although this is a typical characteristic of fusiform aneurysms, the same phenomenon may occur in giant aneurysms with very broad necks. Under such circumstances, any lack of sufficient platelet inhibition may result in either distal embolization or FD thrombosis.

Because histologic findings were similar in anterior and posterior fossa aneurysms, these phenomena are likely related to the fusiform morphology rather than the location of the aneurysms.

This work was limited by the small number of samples and warrants further experimental and clinical pathologic studies. High-resolution vessel wall imaging and sequential MR imaging of giant aneurysms after FD treatment may help us to understand more thoroughly the process of aneurysm thrombosis and the role of the aneurysm wall in the thrombotic process.

\section{CONCLUSIONS}

The results of this study confirm the hypothesis that in GFAs, thrombus organization and intimal coverage of the FD may not occur for more than 1 year, which leads to a prolonged risk of aneurysm rupture and FD thrombosis. The lack of thrombus organization does not seem to be related to FD design or aneurysm location and probably results from wall degeneration of partially thrombosed GFAs. Nonfilling of the aneurysm by angiography should not be interpreted as a sign of aneurysm healing. Because of their inefficacy, FDs should be considered for this pathology only if treatment is needed and no other option is available. 


\section{ACKNOWLEDGMENTS}

The authors sincerely acknowledge the contribution of Surpass Ltd. and Ajay Kumar Wakhloo for providing material support and advising in the procedures.

Disclosures: Istvan Szikora—UNRELATED: Board Membership: Covidien Neurovascular; Consultancy: Covidien Neurovascular, Stryker Neurovascular, and Codman Neurovascular.

\section{REFERENCES}

1. Becske T, Kallmes DF, Saatci I, et al. Pipeline for uncoilable or failed aneurysms: results from a multicenter clinical trial. Radiology 2013; 267:858-68 CrossRef Medline

2. Lylyk P, Miranda C, Ceratto R, et al. Curative endovascular reconstruction of cerebral aneurysms with the Pipeline embolization device: the Buenos Aires experience. Neurosurgery 2009;64:632-42; discussion 642-43; quiz N6 CrossRef Medline

3. Szikora I, Berentei Z, Kulcsar Z, et al. Treatment of intracranial aneurysms by functional reconstruction of the parent artery: the Budapest experience with the Pipeline embolization device. AJNR Am J Neuroradiol 2010;31:1139-47 CrossRef Medline

4. Nelson PK, Lylyk P, Szikora I, et al. The Pipeline embolization device for the intracranial treatment of aneurysms trial. AJNR Am J Neuroradiol 2011;32:34-40 CrossRef Medline

5. Saatci I, Yavuz K, Ozer C, et al. Treatment of intracranial aneurysms using the Pipeline flow-diverter embolization device: a single-center experience with long-term follow-up results. AJNR Am J Neuroradiol 2012;33:1436-46 CrossRef Medline

6. Piano M, Valvassori L, Quilici L, et al. Midterm and long-term follow-up of cerebral aneurysms treated with flow diverter devices: a single-center experience. J Neurosurg 2013;118:408-16 CrossRef Medline

7. Szikora I, Marosfoi M, Salomváry B, et al. Resolution of mass effect and compression symptoms following endoluminal flow diversion for the treatment of intracranial aneurysms. AJNR Am J Neuroradiol 2013;34:935-39 CrossRef Medline

8. Sahlein DH, Fouladvand M, Becske T, et al. Neuro-ophthalmologic outcomes from the Pipeline for uncoilable or failed aneurysms. J Neurosurg 2015. In press

9. Fiorella D, Hsu D, Woo HH, et al. Very late thrombosis of a Pipeline embolization device construct: case report. Neurosurgery 2010;67(3 suppl):onsE313-14; discussion onsE314 CrossRef Medline

10. Siddiqui AH, Abla AA, Kan P, et al. Panacea or problem: flow diverters in the treatment of symptomatic large or giant fusiform vertebrobasilar aneurysms. J Neurosurg 2012;116:1258-66 CrossRef Medline

11. Park SH, Yim MB, Lee CY, et al. Intracranial fusiform aneurysms: it's pathogenesis, clinical characteristics and managements. $J \mathrm{Ko}$ rean Neurosurg Soc 2008;44:116-23 CrossRef Medline

12. Findlay JM, Hao C, Emery D. Non-atherosclerotic fusiform cerebral aneurysms. Can J Neurol Sci 2002;29:41-48 CrossRef Medline

13. Nakayama Y, Tanaka A, Kumate S, et al. Giant fusiform aneurysm of the basilar artery: consideration of its pathogenesis. Surg Neurol 1999;51:140-45 CrossRef Medline

14. Drake CG, Peerless SJ. Giant fusiform intracranial aneurysms: re- view of 120 patients treated surgically from 1965 to 1992 . J Neurosurg 1997;87:141-62 CrossRef Medline

15. Nakatomi H, Segawa H, Kurata A, et al. Clinicopathological study of intracranial fusiform and dolichoectatic aneurysms: insight on the mechanism of growth. Stroke 2000;31:896-900 CrossRef Medline

16. Gobin YP, Viñuela F, Gurian JH, et al. Treatment of large and giant fusiform intracranial aneurysms with Guglielmi detachable coils. J Neurosurg 1996;84:55-62 CrossRef Medline

17. Lubicz B, Collignon L, Lefranc F, et al. Circumferential and fusiform intracranial aneurysms: reconstructive endovascular treatment with self-expandable stents. Neuroradiology 2008;50: 499-507 CrossRef Medline

18. Devulapalli KK, Chowdhry SA, Bambakidis NC, et al. Endovascular treatment of fusiform intracranial aneurysms. J Neurointerv Surg 2013;5:110-16 CrossRef Medline

19. Fiorella D, Woo HH, Albuquerque FC, et al. Definitive reconstruction of circumferential, fusiform intracranial aneurysms with the Pipeline embolization device. Neurosurgery 2008;62:1115-20; discussion 1120-21 CrossRef Medline

20. Fiorella D, Albuquerque F, Gonzalez F, et al. Reconstruction of the right anterior circulation with the Pipeline embolization device to achieve treatment of a progressively symptomatic, large carotid aneurysm. J Neurointerv Surg 2010;2:31-37 CrossRef Medline

21. Fiorella D, Kelly ME, Albuquerque FC, et al. Curative reconstruction of a giant midbasilar trunk aneurysm with the Pipeline embolization device. Neurosurgery 2009;64:212-17; discussion 217 CrossRef Medline

22. Kulcsár Z, Houdart E, Bonafé A, et al. Intra-aneurysmal thrombosis as a possible cause of delayed aneurysm rupture after flow-diversion treatment. AJNR Am J Neuroradiol 2011;32:20-25 CrossRef Medline

23. Molyneux AJ, Ellison DW, Morris J, et al. Histological findings in giant aneurysms treated with Guglielmi detachable coils: report of 2 cases with autopsy correlation. J Neurosurg 1995;83:129-32 CrossRef Medline

24. Kallmes DF, Ding YH, Dai D, et al. A new endoluminal, flow-disrupting device for treatment of saccular aneurysms. Stroke 2007;38: 2346-52 CrossRef Medline

25. Kadirvel R, Ding YH, Dai D, et al. Cellular mechanisms of aneurysm occlusion after treatment with a flow diverter. Radiology 2014;270: 394-99 CrossRef Medline

26. Szikora I, Seifert P, Hanzely Z, et al. Histopathologic evaluation of aneurysms treated with Guglielmi detachable coils or Matrix detachable microcoils. AJNR Am J Neuroradiol 2006;27:283-88 Medline

27. Frösen J, Tulamo R, Paetau A, et al. Saccular intracranial aneurysm: pathology and mechanisms. Acta Neuropathol 2012;123:773-86 CrossRef Medline

28. Marbacher S, Marjamaa J, Bradacova K, et al. Loss of mural cells leads to wall degeneration, aneurysm growth, and eventual rupture in a rat aneurysm model. Stroke 2014;45:248-54 CrossRef Medline

29. Fontaine V, Jacob MP, Houard X, et al. Involvement of the mural thrombus as a site of protease release and activation in human aortic aneurysms. Am J Pathol 2002;161:1701-10 CrossRef Medline

30. McArthur C, Teodorescu V, Eisen L, et al. Histopathologic analysis of endovascular stent grafts from patients with aortic aneurysms: does healing occur? J Vasc Surg 2001;33:733-38 CrossRef Medline 